\title{
FLAX-SEED OIL AND LACTOBACILLUS PLANTARUM SUPPLEMENTATION MODULATE TLR AND NF-KB GENE EXPRESSION IN ENTEROTOXIGENIC ESCHERICHIA COLI CHALLENGED GNOTOBIOTIC PIGS
}

\author{
Mária CHYTILOVÁ ${ }^{1,2}$, Radomíra NEMCOVÁ ${ }^{1}$, Soňa GANCARČíKOVÁ ${ }^{1}$, \\ Dagmar MUdROŇOVÁ ${ }^{1}$ and L'udmila TKÁČIKOVÁ ${ }^{1 *}$

\begin{abstract}
${ }^{1}$ Department of Microbiology and Immunology, University of Veterinary Medicine and of Experimental Medicine, Faculty of Medicine, P. J. Šafárik University in Košice, Košice, Slovak Republic
\end{abstract} \\ Pharmacy, Komenského 73, 04181 Košice, Slovak Republic; ${ }^{2}$ Current address: Department
}

(Received 31 March 2014; accepted 25 June 2014)

\begin{abstract}
The present study analyses the effect of flax-seed oil rich in n-3 polyunsaturated fatty acids (PUFAs), the probiotic strain Lactobacillus plantarum - Biocenol $^{\mathrm{TM}}$ LP96 and their combination on the expression level of selected Toll-like receptor (TLR) genes (TLR2, TLR4, TLR5, TLR9) and their downstream molecules (myeloid differentiation factor 88, MyD88; nuclear factor- $\kappa \mathrm{B}, \mathrm{NF}-\kappa \mathrm{B}$ ) in the jejunum of gnotobiotic pigs challenged with enterotoxigenic Escherichia coli (ETEC). The results show that both immunomodulators are able to modulate the RNA level of at least one of the target molecules and thus regulate pathogeninduced inflammation. We confirmed that not only probiotic lactobacilli or flaxseed oil alone but also their synergistic action has great potential in the prevention and treatment of porcine colibacillosis. The results give an insight into one of the possible mechanisms by which natural agents, such as probiotic lactobacilli and flax-seed oil, exert their immunoregulatory properties during pathogen-induced inflammation.
\end{abstract}

Key words: Flax-seed oil, lactobacilli, ETEC, gene expression, TLR, NF-кB

Toll-like receptors (TLRs) represent a large family of evolutionarily conserved receptors, which play an important role in protection against invading microorganisms. After pathogen recognition, TLRs trigger signalling cascades leading to the activation of nuclear factor- $\kappa \mathrm{B}(\mathrm{NF}-\kappa \mathrm{B})$, which in turn activates genes involved in the inflammatory response (Akira et al., 2006). In the context of an enterotoxigenic Escherichia coli (ETEC) infection, increased expression of several TLRs (TLR2, TLR3, TLR4, TLR5, TLR8) in porcine intestinal cells after bacterial or lipopolysaccharide (LPS) stimulation (Moue et al., 2008) has been reported. Similarly, altered expression of at least one TLR (TLR4, TLR5, TLR9)

*Corresponding author; E-mail: Ludmila.Tkacikova@uvlf.sk; Phone: 00421 (915) 984-603 
has been observed in porcine blood mononuclear cells in response to LPS and other bacterial ligands ( $\mathrm{CpG}$, lipoteichoic acid, peptidoglycan) (Raymond and Wilkie, 2005).

Apart from playing a role in pathogen recognition, TLRs also react with structural components of health-promoting probiotic microorganisms that possess various immunomodulatory effects (Takeda et al., 1997; Kitazawa et al., 1998, 2001; Sato et al., 2004; Iliev et al., 2005). In intestinal dendritic cells, recognition of commensal-bacterial molecular patterns via TLRs (especially TLR2, TLR4, TLR9) leads to their maturation and to the release of cytokines, which coordinate the differentiation of naive T-helper cells (Th0) into a mature Th1, Th2 or Th3/Treg subpopulation (Rescigno et al., 2001; Rachmilewitz et al., 2004). Up-regulation of TLR gene expression and cytokine production, induced by probiotic lactobacilli (Lactobacillus bulgaricus and L. gasseri), has also been observed in immature intestinal tissue and gut-associated lymphoid tissue of presuckling newborn swine (Tohno et al., 2006). Unlike pathogens, probiotic bacteria do not cause inflammation, because they can regulate the immune response via a complex of mechanisms. This has been confirmed in human monocyte-like cells, where preventive treatment with genomic DNA of probiotic lactobacilli ( $L$. plantarum), followed by LPS stimulation, led to the reduction of some TLRs, inhibition of NF- $\mathrm{kB}$ and mitogen-activated protein kinase (MAPK) signalling pathways, and induction of TLR-negative regulators (Kim et al., 2012).

Similarly, substances like polyunsaturated fatty acids (PUFAs) are also able to affect TLR and NF-кB levels (Lee et al., 2003a, 2003b; Weatherill et al., 2005; Lu et al., 2007). Furthermore, it has been demonstrated that PUFAs (especially n-3 PUFAs) can potentiate the immunomodulatory properties of probiotic lactobacilli via stimulation of bacterial adhesion to the intestinal wall (Ringø et al., 1998; Bomba et al., 2003; Nemcová et al., 2012). This mechanism is not fully understood yet; however, Kankaanpää et al. (2001) have found that n-3 PUFAs are able to modulate the composition of the gastrointestinal flora through their direct effect on the binding sites on epithelial cells. Based on this background and our previous results from the same experiment concerning cytokine immune response (Chytilová et al., 2013), we decided to analyse the effect of both immunomodulators (flaxseed oil rich in n-3 PUFAs and the probiotic strain of L. plantarum - Biocenol ${ }^{\mathrm{TM}}$ LP96) alone and in combination on the gene expression level of selected TLRs (TLR2, TLR4, TLR5 and TLR9), their main adaptor molecule MyD88 and transcription factor NF- $\mathrm{kB}$ in the jejunum of gnotobiotic pigs challenged with ETEC O8: K88ab: H9:ent ${ }^{-}$.

\section{Materials and methods}

The experiment with newborn gnotobiotic piglets was carried out at the Institute of Microbiology and Gnotobiology, University of Veterinary Medicine 
and Pharmacy, Košice, Slovakia. The State Veterinary and Food Administration of the Slovak Republic approved the experimental protocol (number 2931/09-221) and the animals were handled and sacrificed in accordance with the guidelines established by the ethics committee. The experiment was carried out on 18 gnotobiotic piglets of the Slovak White $\times$ Landrace breed. Gnotobiotic piglets were prepared and reared exactly as described in our previous study (Chytilová et al., 2013). The piglets did not receive colostrum and were fed autoclaved milk substitute (Sanolac Ferkel, Germany) six times daily, ad libitum.

\section{Flax-seed oil and bacterial strains}

Flax-seed oil (cultivar Flanders) was obtained and analysed by AGRITEC (Czech Republic) and it contained $45.78 \%$ of lipids in dry matter basis. The composition of lipids was as follows: palmitic acid (C16:0) - 5.08\%; stearic acid (C18:0) - 3.67\%; oleic acid (C18:1) - 18.39\%; linoleic acid (C18:2) - 16.08\%; linolenic acid (C18:3) - 56.78\%.

The L. plantarum - Biocenol ${ }^{\mathrm{TM}}$ LP96 strain was isolated from the gut contents of healthy suckling piglets. The strain was characterised by strong adherence to epithelial cells from the porcine intestine, by inhibitory activity against Escherichia coli O8:K88ab:H9 in vitro, and production of hydrogen peroxide and organic acids (Nemcová et al., 1997). These properties as well as the significant immunomodulatory action of this strain were subsequently confirmed during in vivo experiments in pigs (Nemcová et al., 2012; Chytilová et al., 2013). The strain was grown in de Man, Rogosa and Sharpe broth (MRS; Merck, Germany) for $18 \mathrm{~h}$ at $37^{\circ} \mathrm{C}$. The optical density at $640 \mathrm{~nm}$ of the bacterial culture was adjusted to give approximately $1 \times 10^{9}$ colony forming units $(\mathrm{CFU}) / \mathrm{mL}$ (Specol EK, Carl Zeiss, Jena, Germany).

The E. coli $\mathrm{O} 8: \mathrm{K} 88 \mathrm{ab}: \mathrm{H} 9$ strain, without enterotoxin production, was obtained from the Laboratory of Immunology and Gnotobiology, Institute of Microbiology, Czech Academy of Sciences, Prague, Czech Republic. An overnight broth culture of $E$. coli $(1 \mathrm{~mL})$ was inoculated into $50 \mathrm{~mL}$ Trypticase soy broth (Oxoid Unipath Ltd., Basingstoke, UK) and cultivated at $37^{\circ} \mathrm{C}$ in a water bath shaker (JULABO SW 2C, Labor Technic GMBH Selbach, Germany) for approximately $2 \mathrm{~h}$ to an optical density 0.5 at $640 \mathrm{~nm}$ (corresponding to $1 \times 10^{8}$ $\mathrm{CFU} / \mathrm{mL}$ ). Subsequently, the bacterial culture was diluted in isotonic saline to obtain a final concentration of $1 \times 10^{5} \mathrm{CFU} / \mathrm{mL}$.

\section{Experimental design}

The newborn germ-free piglets were divided into four groups: $\mathrm{K}$ (control, $\mathrm{n}=3$ ), L (Lactobacillus plantarum - Biocenol ${ }^{\mathrm{TM}}$ LP 96, $\mathrm{n}=5$ ), MK (flax-seed oil, $\mathrm{n}=5$ ), and LMK (L. plantarum and flax-seed oil, $\mathrm{n}=5$ ). The piglets from the LMK and $\mathrm{L}$ groups were inoculated orally with $2 \mathrm{~mL}$ of $L$. plantarum $\left(1 \times 10^{9} \mathrm{CFU} / \mathrm{mL}\right)$ 
CHYTILOVÁ et al

each day. In addition, flax-seed oil was administered to the animals of Groups LMK and MK once a day at a dose of $0.5 \mathrm{~mL}$. At the age of five days, the piglets from all groups were challenged orally with $2 \mathrm{~mL}$ of E. coli O8:K88ab:H9:ent ${ }^{-}$ $\left(1 \times 10^{5} \mathrm{CFU} / \mathrm{mL}\right)$. All piglets from all groups were sacrificed on day 9 (the 4 th day after $E$. coli inoculation) by intracardiac euthanasia with $1 \mathrm{~mL} / \mathrm{kg}$ b. w. T61 ${ }^{\circledR}$ (Intervet International BV, Boxmeer, The Netherlands). The gastrointestinal tract was immediately removed and the cranial mid-part of the jejunum was used for further gene expression analysis.

\section{Gene expression analysis}

Intestinal tissues $(40 \mathrm{mg})$ were homogenised and total RNA was isolated using PureZOL ${ }^{\mathrm{TM}}$ (BioRad, USA). RNA quality and purity was determined, measuring absorption at 260/280 nm using a Nanodrop (NanoDrop Technologies, Inc., USA). Before cDNA synthesis, all RNA samples were treated with a TURBO DNA-free ${ }^{\mathrm{TM}} \mathrm{Kit}$ (Ambion). One $\mu \mathrm{g}$ of RNA was used to generate firststrand cDNA using RevertAid Premium Reverse Transcriptase (Fermentas Inc., Germany), with a blend of oligo(dT) ${ }_{18}$ and random hexamer primers (Fermentas).

Table 1

Sequences of primers used in RT-qPCR

\begin{tabular}{llll}
\hline Gene & \multicolumn{1}{c}{ Forward primer $\left(5^{\prime}-3^{\prime}\right)$} & \multicolumn{1}{c}{ Reverse primer (5'-3') } & \multicolumn{1}{c}{ References } \\
\hline TLR2 & ACATGAAGATGATGTGGGCC & TAGGAGTCCTGCTCACTGTA & Moue et al. (2008) \\
TLR4 & CTCTGCCTTCACTACAGAGA & CTGAGTCGTCTCCAGAAGAT & Moue et al. (2008) \\
TLR5 & TTTCTGGCAATGGCTGGACA & TGGAGGTTGTCAAGTCCATG & Moue et al. (2008) \\
TLR9 & GTGGAACTGTTTTGGCATC & CACAGCACTCTGAGCTTTGT & Moue et al. (2008) \\
MYD88 & TGAAGCAGCAGCAGGAGGCA & TCGCTGGGGCAGTAGCAGATGA & This study \\
NF-кB & GGAGCTGGTGGAGGCCCTGA & GCCTTGTGGAGGCAGGCGAG & This study \\
$\beta$-actin & CATCACCATCGGCAACGA & GCGTAGAGGTCCTTCCTGATGT & Moue et al. (2008) \\
\hline
\end{tabular}

Primers for the amplification of TLR2, TLR4, TLR5, TLR9 and $\beta$-actin genes were designed according to Moue et al. (2008) (Table 1). Primers for the amplification of MYD88 and NF- $\mathrm{KB}$ genes were designed using the gene sequences of MYD88 (NM001099923.1) and NF- $\mathrm{kB}$ (NM001048232.1) from the GenBank database and using Primer-Blast software. RT-qPCRs were performed in an iCycler iQ (BioRad, USA) in $25 \mu \mathrm{L}$ reaction volume containing $1 \times \mathrm{iQ}^{\mathrm{TM}}$ SYBR Green Supermix ( $0.2 \mathrm{mM}$ dNTP, $3 \mathrm{mM} \mathrm{MgCl} 2$, BioRad), $6 \mu \mathrm{L}$ nucleasefree water, $0.4 \mu \mathrm{M}$ forward and reverse primer and $6 \mu \mathrm{L}$ of cDNA. All reactions were performed in triplicates. The reaction conditions were as follow: $95^{\circ} \mathrm{C} 3 \mathrm{~min}$, 40 cycles $\left[94^{\circ} \mathrm{C} 15 \mathrm{~s}, 58^{\circ} \mathrm{C}\right.$ (for TLRs) or $60^{\circ} \mathrm{C}$ (for MYD88 and NF-kB) $30 \mathrm{~s}$, $\left.72{ }^{\circ} \mathrm{C} 30 \mathrm{~s}\right], 72{ }^{\circ} \mathrm{C} 15 \mathrm{~min}$ followed by melting curve analysis to confirm ampli- 
fication of a specific product. $\beta$-actin was used as a housekeeping gene for internal control. Each assay included a negative control without cDNA template. Relative expression levels of target and $\beta$-actin mRNA were evaluated by the $2^{\Delta \Delta \mathrm{CT}}$ method.

\section{Statistical analysis}

Data were evaluated with GraphPadPrism version 3.00 by one-way analysis of variance (ANOVA) followed by a Tukey's multiple comparison test.

\section{Results}

In this study we examined if the application of flax-seed oil rich in $n-3$ PUFAs and the probiotic strain L. plantarum alone or in combination alters gene expression of TLRs and their downstream molecules in ETEC-challenged gnotobiotic pigs. Based on our previous microbiological observations from the same experimental conditions (Nemcová et al., 2012), confirming that combined treatment had the most significant effects in the jejunum, we used samples from the same part of the intestine for the gene expression analysis.

In our study, RT-qPCR showed that the preventive administration of $L$. plantarum (L, $0.11 \pm 0.02)$ and its combination with flax-seed oil (LMK, $0.22 \pm$ 0.03 ) to gnotobiotic pigs followed by ETEC infection led to significant downregulation of the TLR2 mRNA level compared to the control group $(\mathrm{K}, 1.02 \pm$ $0.13)$ and the group fed with flax-seed oil alone (MK, $0.96 \pm 0.05)(\mathrm{P}<0.001)$ (Fig. 1a). On the other hand, piglets in the MK group had a significantly higher amount of jejunal TLR4 mRNA $(1.54 \pm 0.23)$ compared with the control $(1.01 \pm$ 0.12 ) and piglets from the other experimental groups (L, $1.03 \pm 0.10$; LMK, $0.88 \pm 0.06)(\mathrm{P}<0.001)$ (Fig. 1b). However, simultaneous administration of both immunomodulators (LMK group) resulted in the decrease of TLR4 transcript to below the basal level (LMK, $0.88 \pm 0.06$ ), although this was not statistically significant. Similar results were found in the case of TLR9, where flax-seed oil supplemented to the diet increased the amount of this transcript in the jejunum of gnotobiotic pigs $(1.43 \pm 0.28)$ (MK vs. $\mathrm{K}, \mathrm{P}<0.05$; MK vs. $\mathrm{L}$ and $\mathrm{LMK}, \mathrm{P}<$ 0.001) (Fig. 1c). In the LMK group we found a slight down-regulation of TLR9 $(0.81 \pm 0.11)$ and a similar result was obtained in pigs fed with $L$. plantarum $(0.87 \pm 0.13)$, although without statistical significance in both groups. In the case of TLR5, all three types of preventive administration resulted in a significant down-regulation of this transcript in comparison with the control piglets (L, $0.78 \pm$ 0.11 ; L vs. $\mathrm{K}, \mathrm{P}<0.05$ ), (MK, $0.84 \pm 0.11$; MK vs. $\mathrm{K}, \mathrm{P}<0.05$ ), with a maximum effect in the group given the combined treatment (LMK, $0.53 \pm 0.08$; LMK vs. K, P < 0.001; LMK vs. L, P < 0.05; LMK vs. MK, P < 0.01) (Fig. 1d). Furthermore, we found a significant suppression of MyD88 gene expression in the group 

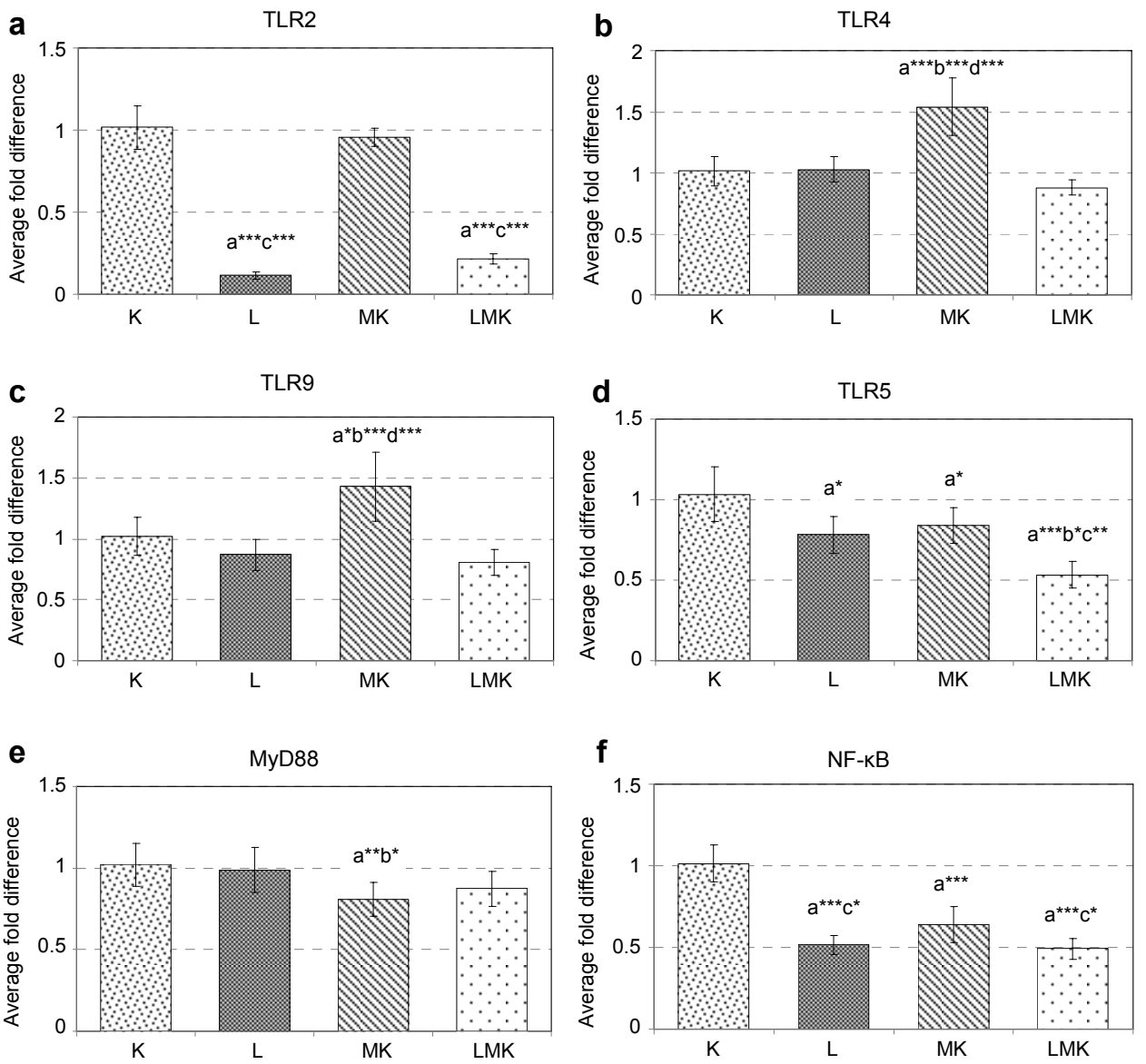

Fig. 1. TLRs (a-d), MyD88 (e) and NF-kB (f) mRNA expression levels normalised to $\beta$-actin (Average fold difference) in ETEC O8:K88ab:H9:ent ${ }^{-}$challenged pigs $(\mathrm{n}=5)$ pretreated with L. plantarum Biocenol ${ }^{\mathrm{TM}}$-LP96 (L), flax-seed oil rich in n-3 PUFAs (MK) or their combination (LMK). K - control, L - L. plantarum, MK - flax-seed oil, LMK - L. plantarum + flax-seed oil, ${ }^{a}$ - significantly different from Group $K,{ }^{b}-$ significantly different from Group $L,{ }^{c}-$ significantly different from Group MK, ${ }^{\mathrm{d}}-$ significantly different from Group LMK, ${ }^{*}-\mathrm{P}<0.05,{ }^{* * *}-\mathrm{P}<0.01$, $-\mathrm{P}<0.001$

with flax-seed oil pre-treatment $(0.81 \pm 0.10$; MK vs. $\mathrm{K}, \mathrm{P}<0.01$; MK vs. $\mathrm{L}, \mathrm{P}<$ $0.05)$. This tendency was also found in the $\mathrm{L}(0.99 \pm 0.14)$ and LMK groups $(0.87 \pm 0.11)$ (Fig. 1e). In the case of transcription factor NF- $\mathrm{kB}$, the most significant decrease of this transcript was observed in the jejunum of pigs fed a diet supplemented with L. plantarum $(0.52 \pm 0.06)$, and also in the group simultaneously administered both tested immunomodulators $(0.49 \pm 0.06)(\mathrm{L}$ and LMK vs. K, $\mathrm{P}<0.001 ; \mathrm{L}$ and LMK vs. MK, $\mathrm{P}<0.05$ ) (Fig. 1f). 


\section{Discussion}

TLRs play an important role in the defence against invading microorganisms. After pathogen recognition, TLRs trigger signalling cascades leading to the activation of NF- $\kappa \mathrm{B}$, which in turn activates genes involved in the inflammatory response (Akira et al., 2006). In the present study we demonstrated that the application of L. plantarum, flax-seed oil and their combination alters the RNA level of at least one TLR, their main adaptor molecule MyD88 and transcription factor NF- $\mathrm{KB}$ in the jejunum of gnotobiotic pigs, where the most important pathophysiological changes in ETEC infections take place.

In this study, RT-qPCR showed that the administration of L. plantarum to gnotobiotic pigs followed by ETEC infection resulted in a significant downregulation of TLR2, TLR5 and NF- $\kappa B$. In addition, the same group (L) manifested a similar trend in the case of TLR9. Currently, only a few studies are known which deal with the immunomodulatory effect of probiotic lactobacilli at the TLR level during porcine colibacillosis. There is an in vitro study by Kim et al. (2012), where the pre-treatment of THP-1 cells with $L$. plantarum gDNA and their subsequent stimulation with LPS resulted in suppression of TLR2, TLR4, TLR9 and NF- $\mathrm{KB}$ transcripts. On the other hand, in their in vivo study Li et al. (2012) showed that the preventive administration of L. rhamnosus ACTT 7469 to weanlings for one week followed by ETEC infection led to a significant upregulation of TLR2 and to a statistically not significant reduction of TLR4 and TLR5 mRNA in the jejunum of the pigs treated. However, differences between the results of each experimental study are due to various factors such as the type of experimental scheme (in vitro or in vivo), the type and concentration of the probiotic strain applied, and the developmental level of pigs (sucklings/ weanlings) in the case of in vivo studies.

Furthermore, unlike the L group in our study we also found a significant decrease of the MyD88 mRNA level in pigs after flax-seed oil stimulation, despite the fact that the expression of this adaptor protein is lower in the gut of newborn swine than in other tissues (Tohno et al., 2007). On the other hand, preventive administration of flax-seed oil led to the increase of TLR4 and TLR9 gene expression. The balance between saturated and unsaturated fatty acids, which can be altered by the types of dietary fat consumed, can also affect the induction of TLR-mediated immune response (Weatherill et al., 2005). Several studies have demonstrated that saturated fatty acids activate TLR2 and TLR4, whereas unsaturated fatty acids inhibit the agonist-induced activation of TLRs (Lee et al., 2001, 2003a, 2004; Weatherill et al., 2005). We suppose that the increased expression of TLR4 detected in our study on gnotobiotic pigs (MK) may be affected by saturated fatty acids, which were also present in flax-seed oil. The immunomodulatory effect may also be influenced by other components in the flax-seed oil, e.g. by phytosterols. Brüll et al. (2010) demonstrated TLR2 activa- 
tion in human peripheral blood mononuclear cells by plant stanols and plant sterols. On the other hand, the same authors did not confirm the activation of TLR4. These discrepancies could be due to different experimental conditions (in vivo/ex vivo study), different cell types (intestinal cells/blood cells) and/or the different form of tested substances (flax-seed oil/pure stanols and sterols). However, in our study, flax-seed oil alone (MK) and particularly its combination with L. plantarum (LMK) administered to gnotobiotic pigs challenged with ETEC resulted in a significant decrease of TLR5 and NF- $\mathrm{kB}$ mRNA level. In addition, in the LMK group we found a similar trend in the case of TLR4 and TLR9 transcripts.

Even though there are several studies focusing on the effect of probiotic lactobacilli on TLR levels during porcine colibacillosis (Kim et al., 2012; Li et al., 2012), this area of the study is not sufficiently covered, and in the case of combined treatment with n-3 PUFAs studies are fully absent. However, the results presented here are in correlation with cytokine gene expression analysis from a previous experiment (Chytilová et al., 2013), for example: down-regulation of TLR2, TLR5 and NF- $\mathrm{kB}$, and decrease of pro-inflammatory cytokine mRNA (IL- $1 \alpha$, IL8) found in the L and LMK groups; increase of TLR4 transcript, induced by flaxseed oil, and up-regulation of both inflammatory mediators (IL-1 $\alpha$, IL-8) detected in the jejunum of the same piglets. Moreover, significant results detected in the LMK group are consistent with the results of previous bacteriological analysis on the same piglets (Nemcová et al., 2012), which confirmed that supplementation of flax-seed oil rich in n-3 PUFAs resulted in significantly higher numbers of $L$. plantarum and lower numbers of ETEC adhered to the jejunal mucosa.

In conclusion, we confirmed that the application of L. plantarum and flaxseed oil rich in n-3 PUFAs can modulate mRNA levels of some TLRs, their main adaptor molecule MyD88 and transcription factor NF- $\mathrm{kB}$ in various ways, and thus regulate pathogen-induced inflammation in the jejunum of gnotobiotic pigs. These results clearly confirm that not only immunomodulators alone (L. plantarum or flax-seed oil monotherapy) but also their synergistic action has a great potential in the prevention and treatment of porcine colibacillosis. Since only few studies on similar subjects have been published, these results can contribute to our understanding of the molecular mechanisms underlying the mode of action of these immunomodulators.

\section{Acknowledgements}

We would like to thank Mangesh Bhide, DVM, PhD, Head of the Laboratory of Biomedical Microbiology and Immunology, Institute of Immunology, University of Veterinary Medicine and Pharmacy in Košice for help with the molecular analysis. This work was supported by the project from the Agency of the Slovak Ministry of Education for the Structural Funds of the EU ITMS: 26220220185, by the project SK0021 (Co-financing through the European Economic Area financial mechanism, the Norwegian financial mechanism and the state budget of the Slovak Republic) and by the VEGA projects No. 1/0435/11 and VEGA 1/0834/12. 


\section{References}

Akira, S., Uematsu, S. and Takeuchi, O. (2006): Pathogen recognition and innate immunity. Cell 124, 783-801.

Bomba, A., Nemcova, R., Gancarcikova, S., Herich, R., Pistl, J., Revajova, V., Jonecova, Z., Bugarsky, A., Levkut, M., Kastel, R., Baran, M., Lazar, G., Hluchy, M., Marsalkova, S. and Posivak, J. (2003): The influence of omega-3 polyunsaturated fatty acids (omega-3 PUFA) on lactobacilli adhesion to the intestinal mucosa and on immunity in gnotobiotic piglets. Berl. Münch. Tierärztl. Wschr. 116, 312-316.

Brüll, F., Mensink, R. P., van den Hurk, K., Duijvestijn, A. and Plat, J. (2010): TLR2 activation is essential to induce a Th1 shift in human peripheral blood mononuclear cells by plant stanols and plant sterols. J. Biol. Chem. 285, 2951-2958.

Chytilová, M., Mudroňová, D., Nemcová, R., Gancarčíková, S., Buleca, V., Koščová, J. and Tkáčiková, L. (2013): Anti-inflammatory and immunoregulatory effects of flax-seed oil and Lactobacillus plantarum - Biocenol ${ }^{\mathrm{TM}}$ LP96 in gnotobiotic pigs challenged with enterotoxigenic Escherichia coli. Res. Vet. Sci. 95, 103-109.

Iliev, I. D., Kitazawa, H., Shimosato, T., Katoh, S., Morita, H., He, F., Hosoda, M. and Saito, T. (2005): Strong immunostimulation in murine immune cells by Lactobacillus rhamnosus GG DNA containing novel oligodeoxynucleotide pattern. Cell. Microbiol. 7, 403-414.

Kankaanpää, P. E., Salminen, S. J., Isolauri, E. and Lee, Y. K. (2001): The influence of polyunsaturated fatty acids on probiotic growth and adhesion. FEMS Microbiol. Lett. 194, 149-153.

Kim, C. H., Kim, H. G., Kim, J. Y., Kim, N. R., Jung, B. J., Jeong, J. H. and Chung, D. K. (2012): Probiotic genomic DNA reduces the production of pro-inflammatory cytokine tumor necrosis factor-alpha. FEMS Microbiol. Lett. 328, 13-19.

Kitazawa, H., Harata, T., Uemura, J., Saito, T., Kaneko, T. and Itoh, T. (1998): Phosphate group requirement for mitogenic activation of lymphocytes by an extracellular phosphopolysaccharide from Lactobacillus delbrueckii ssp. Bulgaricus. Int. J. Food Microbiol. 40, 169-175.

Kitazawa, H., Ueha, S., Itoh, S., Watanabe, H., Konno, K., Kawai, Y., Saito, T., Itoh, T. and Yamaguchi, T. (2001): AT oligonucleotides inducing B lymphocyte activation exist in probiotic Lactobacillus gasseri. Int. J. Food Microbiol. 65, 149-162.

Lee, J. Y., Plakidas, A., Lee, W. H., Heikkinen, A., Chanmugam, P., Bray, G. and Hwang, D. H. (2003b): Differential modulation of Toll-like receptors by fatty acids: preferential inhibition by n-3 polyunsaturated fatty acids. J. Lipid Res. 44, 479-486.

Lee, J. Y., Sohn, K. H., Rhee, S. H. and Hwang, D. (2001): Saturated fatty acids, but not unsaturated fatty acids, induce the expression of cyclooxygenase-2 mediated through Toll-like receptor 4. J. Biol. Chem. 276, 16683-16689.

Lee, J. Y., Ye, J., Gao, Z., Youn, H. S., Lee, W. H., Zhao, L., Sizemore, N. and Hwang, D. H. (2003a): Reciprocal modulation of Toll-like receptor-4 signaling pathways involving MyD88 and phosphatidylinositol 3-kinase/AKT by saturated and polyunsaturated fatty acids. J. Biol. Chem. 278, 37041-37051.

Lee, J. Y., Zhao, L., Youn, H. S., Weatherill, A. R., Tapping, R., Feng, L., Lee, W. H., Fitzgerald, K. A. and Hwang, D. H. (2004): Saturated fatty acid activates but polyunsaturated fatty acid inhibits Toll-like receptor 2 dimerized with Toll-like receptor 6 or 1. J. Biol. Chem. 279, 16971-16979.

Li, X. Q., Zhu, Y. H., Zhang, H. F., Yue, Y., Cai, Z. X., Lu, Q. P., Zhang, L., Weng, X. G., Zhang, F. J., Zhou, D., Yang, J. C. and Wang, J. F. (2012): Risks associated with high-dose Lactobacillus rhamnosus in an Escherichia coli model of piglet diarrhea: Intestinal microbiota and immune imbalances. PLoS One 7, e40666. doi: 10.1371/journal.pone.0040666.

Lu, J., Jilling, T., Li, D. and Caplan, M. S. (2007): Polyunsaturated fatty acid supplementation alters proinflammatory gene expression and reduces the incidence of necrotizing enterocolitis in a neonatal rat model. Pediatr. Res. 61, 427-432. 
Moue, M., Tohno, M., Shimazu, T., Kido, T., Aso, H., Saito, T. and Kitazawa, H. (2008): Toll-like receptor 4 and cytokine expression involved in functional immune response in an originally established porcine intestinal epitheliocyte cell line. Biochim. Biophys. Acta 1780, 134-144.

Nemcová, R., Borovská, D., Koščová, J., Gancarčíková, S., Mudroňová, D., Buleca, V. and Pistl, J. (2012): The effect of supplementation of flax-seed oil on interaction of Lactobacillus plantarum - Biocenol TM LP96 and Escherichia coli O8:K88ab:H9 in the gut of germ-free piglets. Res. Vet. Sci. 93, 39-41.

Nemcová, R., Lauková, A., Gancarčíková, S. and Kaštel', R. (1997): In vitro studies of porcine lactobacilli for possible probiotic use. Berl. Münch. Tierärztl. Wschr. 110, 413-417.

Rachmilewitz, D., Katakura, K., Karmeli, F., Hayashi, T., Reinus, C., Rudensky, B., Akira, S., Takeda, K., Lee, J., Takabayashi, K. and Raz, E. (2004): Toll-like receptor 9 signaling mediates the anti-inflammatory effects of probiotics in murine experimental colitis. Gastroenterology 126, 520-528.

Raymond, C. R. and Wilkie, B. N. (2005): Toll-like receptor, MHC II, B7 and cytokine expression by porcine monocytes and monocyte-derived dendritic cells in response to microbial pathogen-associated molecular patterns. Vet. Immunol. Immunopathol. 107, $235-247$.

Rescigno, M., Urbano, M., Valzasina, B., Francolini, M., Rotta, G., Bonasio, R., Granucci, F., Kraehenbuhl, J. P. and Ricciardi-Castagnoli, P. (2001): Dendritic cells express tight junction proteins and penetrate gut epithelial monolayers to sample bacteria. Nat. Immunol. 2, 361-367.

Ringø, E., Bendiksen, H. R., Gausen, S. J., Sundsfjord, A. and Olsen, R. E. (1998): The effect of dietary fatty acids on lactic acid bacteria associated with the epithelial mucosa and from faecalia of Arctic charr, Salvelinus alpinus (L.). J. Appl. Microbiol. 85, 855-864.

Sato, T., Nishimura-Uemura, J., Shimosato, T., Kawai, Y., Kitazawa, H. and Saito, T. (2004): Dextran from Leuconostoc mesenteroides augments immunostimulatory effects by the introduction of phosphate groups. J. Food Prot. 67, 1719-1729.

Takeda, K., Saito, T., Kitazawa, H., Uemura, J. and Itoh, T. (1997): Mitogenic activity of whole cells and cell wall components of Lactobacillus acidophilus group lactic acid bacteria on murine spleen and Peyer's patch cells. Milchwissenschaft 52, 21-25.

Tohno, M., Shimazu, T., Aso, H., Kawai, Y., Saito, T. and Kitazawa, H. (2007): Molecular cloning and functional characterization of porcine MyD88 essential for TLR signaling. Cell Mol. Immunol. 4, 369-376.

Tohno, M., Shimosato, T., Moue, M., Aso, H., Watanabe, K., Kawai, Y., Yamaguchi, T., Saito, T. and Kitazawa, H. (2006): Toll-like receptor 2 and 9 are expressed and functional in gutassociated lymphoid tissues of presuckling newborn swine. Vet. Res. 37, 791-812.

Weatherill, A. R., Lee, J. Y., Zhao, L., Lemay, D. G., Youn, H. S. and Hwang, D. H. (2005): Saturated and polyunsaturated fatty acids reciprocally modulate dendritic cell functions mediated through TLR4. J. Immunol. 174, 5390-5397. 